\title{
Formation of Highly Oxidized Molecules from NO3 Radical Initiated Oxidation of Delta-3-Carene : A Mechanistic Study
}

\section{Draper, Danielle C.}

2019-08

Draper, D C , Myllys , N, Hyttinen , N, Moller , K H, Kjaergaard , H G , Fry , J L , Smith , J N \& Kurten , T 2019 , ' Formation of Highly Oxidized Molecules from NO3 Radical Initiated Oxidation of Delta-3-Carene : A Mechanistic Study ' , ACS Earth and Space Chemistry , vol. 3 , no. 8 , pp. 1460-1470 . https://doi.org/10.1021/acsearthspacechem.9b00143

http://hdl.handle.net/10138/318089

https://doi.org/10.1021/acsearthspacechem.9b00143

unspecified

acceptedVersion

Downloaded from Helda, University of Helsinki institutional repository.

This is an electronic reprint of the original article.

This reprint may differ from the original in pagination and typographic detail.

Please cite the original version. 


\section{Formation of Highly Oxidized Molecules from $\mathrm{NO}_{3}$}

\section{Radical Initiated Oxidation of $\Delta$-3-Carene: A}

\section{Mechanistic Study}

Danielle C. Draper ${ }^{\dagger}$, Nanna Myllys ${ }^{\dagger}$, Noora Hyttinen ${ }^{t, *}$, Kristian H. Moller $^{\S}$, Henrik G. Kjaergaard $^{\S}$, Juliane L. Fry ${ }^{*}$, James N. Smith ${ }^{* \dagger}$, Theo Kurtén $*,+$

${ }^{\dagger}$ Department of Chemistry, University of California, Irvine, CA 92697, USA, \$Department of Chemistry, University of Helsinki, FIN-00014 Helsinki, Finland, *Nano and Molecular Systems Research Unit, University of Oulu, FIN-90014 Oulu, Finland, ${ }^{\S}$ Department of Chemistry, University of Copenhagen, DK-2100 Copenhagen Ø, Denmark, ${ }^{*}$ Chemistry Department, Reed College, Portland, OR 97202, USA

KEYWORDS $\mathrm{NO}_{3}$ Radical, Monoterpenes, Computational, Mechanism, SOA Formation

ABSTRACT. $\mathrm{NO}_{3}$ radical oxidation of most monoterpenes is a significant source of secondary organic aerosol (SOA) in many regions influenced by both biogenic and anthropogenic emissions, but there are very few published mechanistic studies of $\mathrm{NO}_{3}$ chemistry beyond simple $1^{\text {st }}$ generation products. Here, we present a computationally-derived mechanism detailing the unimolecular pathways available to the $2^{\text {nd }}$ generation of peroxy radicals following $\mathrm{NO}_{3}$ oxidation of $\Delta$-3-carene, defining generations based on the sequence of peroxy radicals formed rather than number of oxidant attacks. We assess five different types of unimolecular reactions, 
including peroxy and alkoxy radical $\left(\mathrm{RO}_{2}\right.$ and $\left.\mathrm{RO}\right)$ hydrogen shifts, $\mathrm{RO}_{2}$ and $\mathrm{RO}$ ring closing (e.g. endoperoxide formation), and RO decomposition. Rate constants calculated using quantum chemical methods indicate that this chemical system has significant contribution from both bimolecular and unimolecular pathways. The dominant unimolecular reactions are endoperoxide formation, $\mathrm{RO} \mathrm{H}$-shifts, and $\mathrm{RO}$ decomposition. However, the complexity of the overall reaction is tempered as only 1 or 2 radical propagation pathways dominate the fate of each radical intermediate. Chemical Ionization Mass Spectrometry (CIMS) measurements using the $\mathrm{NO}_{3}{ }^{-}$ reagent ion during $\Delta$-3-carene $+\mathrm{NO}_{3}$ chamber experiments show products consistent with each of the three types of unimolecular reactions predicted to be important from the computational mechanism. Moreover, the SIMPOL group contribution method for predicting vapor pressures suggests that a majority of the closed-shell products inferred from these unimolecular reactions are likely to have low enough vapor pressure to be able to contribute to SOA formation.

\section{INTRODUCTION}

The 2013 IPCC assessment report illustrates that the greatest source of uncertainty in global climate modeling comes from aerosol. ${ }^{1}$ Particulate matter in the atmosphere can influence atmospheric radiative balance both directly by scattering or absorbing light and indirectly by affecting the formation, reflectivity, and lifetime of clouds, and it is therefore an important factor limiting our understanding of climate as a whole. Secondary organic aerosol (SOA), which forms through secondary reactions of gas-phase emissions such as oxidation of volatile organic compounds (VOCs), contributes a major fraction of the global submicron aerosol. ${ }^{2}$ It has been shown through numerous field studies, laboratory measurements, and the occasional modeling study that $\mathrm{NO}_{3}$ radical oxidation of monoterpenes is a significant, though often overlooked, source of SOA. ${ }^{3-5}$ For example, Pye et al. ${ }^{4}$ incorporated $\mathrm{NO}_{3}+$ monoterpene chemistry into 
GEOS-Chem, parameterized using laboratory $\mathrm{NO}_{3}+\beta$-pinene SOA yields. ${ }^{6}$ They found that SOA from monoterpenes approximately doubled in regions where monoterpene chemistry is important, comparing to simulations where $\mathrm{NO}_{3}$ chemistry was omitted. However, the significance of this chemistry is complicated by the fact that while most abundantly emitted monoterpenes (e.g. $\beta$-pinene, $\Delta$-3-carene, and limonene) have moderate-to-high SOA yields with $\mathrm{NO}_{3}$ radical, the single most abundantly emitted monoterpene ( $\alpha$-pinene) has a negligible SOA yield with $\mathrm{NO}_{3} \cdot{ }^{3,7}$ This presents a challenge to modelers, since most models don't consider $\mathrm{NO}_{3}$ chemistry and those that do are subject to uncertainties due to poorly understood terpene speciesdependence of SOA formation and corresponding poorly characterized regional variability of SOA precursors.

At a glance, the structural difference between $\alpha$-pinene and other bicyclic monoterpenes that would lead to such large differences in condensable products is not obvious. Structures of two of the most prevalent monoterpenes, $\alpha$-pinene and $\Delta$-3-carene, are shown in Figure 1a, highlighting that these molecules differ only by the location and size of the small secondary ring structure. Both of these molecules are expected to undergo the same known atmospheric oxidation pathways in the gas phase, which is summarized in Figure 1b, where products may contribute to SOA formation or growth through thermodynamic partitioning or reactive uptake. For $\mathrm{NO}_{3}$ radical-initiated oxidation, the $\mathrm{NO}_{3}$ radical adds to the double bond, forming an alkyl radical (R). In the oxygen-rich atmosphere, oxygen rapidly adds to the alkyl radical, forming a peroxy radical $\left(\mathrm{RO}_{2}\right){ }^{8}$ The peroxy radical will likely undergo a bimolecular reaction with another radical species, which, at night when $\mathrm{NO}_{3}$ chemistry is most important, is predominantly $\mathrm{NO}_{3}, \mathrm{HO}_{2}$, or $\mathrm{RO}_{2}$. These reactions lead either to alkoxy radicals (RO), or to closed-shell products like hydroperoxides, alcohols, and aldehydes or ketones. ${ }^{9}$ Under conditions where the $\mathrm{RO}_{2}$ lifetime is 
long enough (on the order of seconds), research in the last few years has demonstrated that peroxy radicals with suitable substituents are able to undergo internal hydrogen shifts, regenerating an alkyl radical, which subsequently forms a new peroxy radical, thus initiating a chain of "autoxidation."10-13 Alkoxy radicals are short-lived, and can either react with oxygen, decompose, or isomerize. RO reactions often lead to closed shell products, though both decomposition and isomerization reactions can also lead to the formation of new alkyl radical, and subsequently peroxy radical, species. ${ }^{14}$ Since multiple cycles of radical propagation reactions may occur before terminating to a closed shell product, we will differentiate between different peroxy or alkoxy radicals as different generations, with the counter triggered by a backward arrow to an $\mathrm{RO}_{2}$ in Figure $1 \mathrm{~b}$.

a)

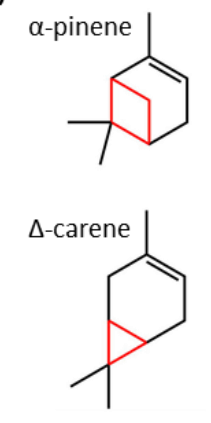

b)

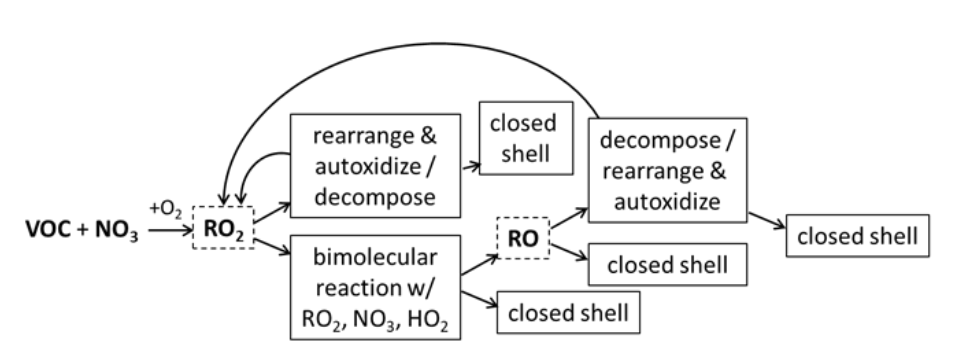

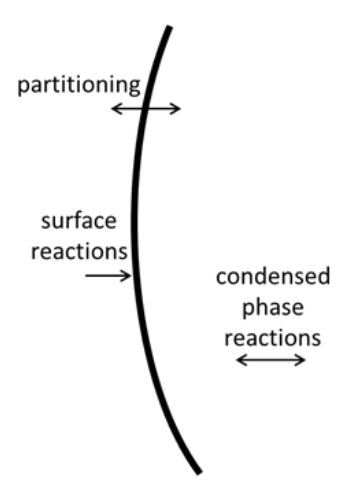

Figure 1. (a) Structures of $\alpha$-pinene and $\Delta$-3-carene highlighting the secondary rings in red to show the only structural variation between the two prevalent monoterpenes, and (b) the general oxidation scheme of $\mathrm{NO}_{3}$ oxidation of volatile organic compounds (VOCs) in the atmosphere. We note that not all pathways are available to all VOCs and some pathways may only become available for later generations of chemistry.

Kurtén et al. ${ }^{15}$ used computational chemistry to compare rate constants for the $1^{\text {st }}$ generation radical $\left(\mathrm{RO}_{2}\right.$ and $\left.\mathrm{RO}\right)$ rearrangement reactions following $\mathrm{NO}_{3}$ oxidation of $\alpha$-pinene and $\Delta-3-$ carene. They found that the potential unimolecular reactions of the $1^{\text {st }}$ generation $\Delta$-3-carene 
peroxy radicals were calculated to be too slow to contribute significantly to the final product distribution. Instead, they identified the $1^{\text {st }}$ generation $\mathrm{NO}_{3}$-substituted $\mathrm{RO}$ as the point where the mechanisms for these two monoterpenes diverge, likely explaining the large difference in SOA yields from the two. As shown in Figure 2, the $\alpha$-pinene-derived $\mathrm{O}_{2} \mathrm{NO}-\mathrm{RO}$ overwhelmingly favors the pathway leading to closed-shell pinonaldehyde, whereas the corresponding $\Delta-3$ carene-derived $\mathrm{O}_{2} \mathrm{NO}-\mathrm{RO}$ is more likely to undergo the radical-retaining pathway, enabling further generations of $\mathrm{RO}_{2}$ and $\mathrm{RO}$ radical rearrangement reactions, which we expect to lead to condensable products. In this study, we expand upon the mechanism presented in Kurtén et al. ${ }^{15}$ and calculate rate constants for various unimolecular reactions of the probable $2^{\text {nd }}$ generation $\mathrm{RO}_{2}$ and $\mathrm{RO}$ generated by $\Delta-3$-carene $+\mathrm{NO}_{3}$ chemistry. We then use these rate constants to predict the most probable $2^{\text {nd }}$ generation reaction products. These predicted products are then compared to compounds observed in the gas phase during chamber experiments of $\Delta$-3-carene + $\mathrm{NO}_{3}$ chemistry.

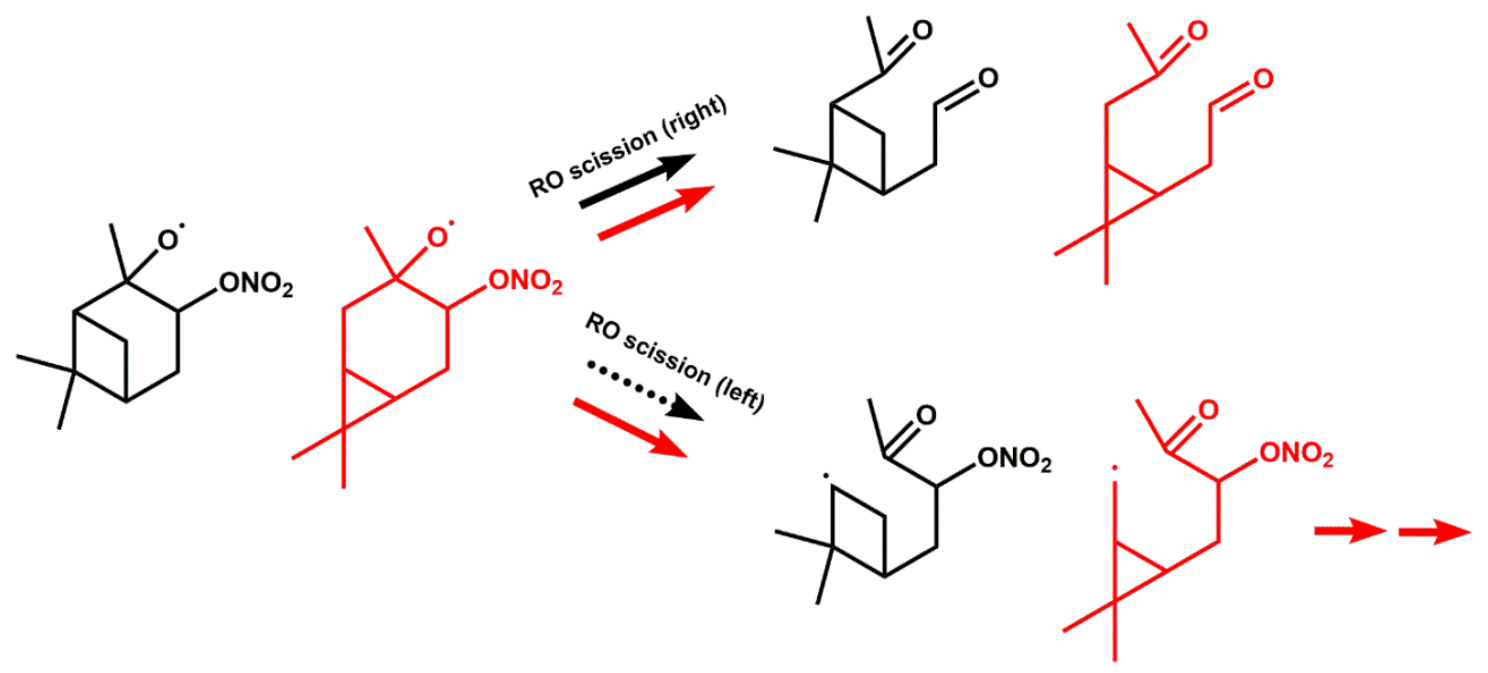

Figure 2. Schematic showing the $\mathrm{RO}$ scission of $\alpha$-pinene $+\mathrm{NO}_{3}$ mechanism (black) compared to $\Delta$-3-carene $+\mathrm{NO}_{3}$ mechanism (red), comparing scission of the right (top) or left (bottom) C-C bond. The dashed arrow for the left scission of the $\alpha$-pinene RO indicates this reaction is not 
expected to be competitive with the right scission due to the unfavorability of the alkyl radical on the strained ring. All other reactions (solid arrows) are expected to occur, with an approximate 50/50 branching for the two $\Delta-3$-carene RO pathways. ${ }^{15}$

Beginning from the radical endpoints from the Kurtén et al. ${ }^{15} \Delta$-3-carene mechanism shown in Figure 3a (mechanism leading to these radical endpoints shown in black in Scheme 1), we developed a computational mechanism for the next generation of chemistry, surveying five different types of unimolecular reactions as shown in Figure $3 \mathrm{~b}$ : internal $\mathrm{RO}_{2}$ and $\mathrm{RO}$ hydrogen shifts ( $\mathrm{H}$-shifts), $\mathrm{RO}_{2}$ and $\mathrm{RO}$ ring closing, and $\mathrm{RO}$ decomposition. Published structure activity relationships (SARs) exist for many, though not all, of the possible reaction pathways assessed in this study. ${ }^{16,17}$ However, explicit calculations of reaction barriers and rate constants for case studies such as this are valuable for several reasons. First, SARs are not available for any $\mathrm{RO}_{2}$ reactions, and existing SARs for alkoxy reactions lack certain substituent effects like the influence of $-\mathrm{ONO}_{2}$ groups on $\mathrm{RO} \mathrm{H}$-shifts. ${ }^{17}$ Additionally, while it has been observed that unimolecular reaction rates increase with increased functionalization, ${ }^{10,13}$ this phenomenon has not been systematically quantified, so computing rate constants for case studies like the complex multifunctional compounds in this study (i.e. a $\mathrm{C}_{10}$ organonitrate) improves our understanding of these processes for more atmospherically relevant species. ${ }^{12}$ Finally, results from this study can provide additional validation of the applicability of existing SARs to more complex molecules. 
a)
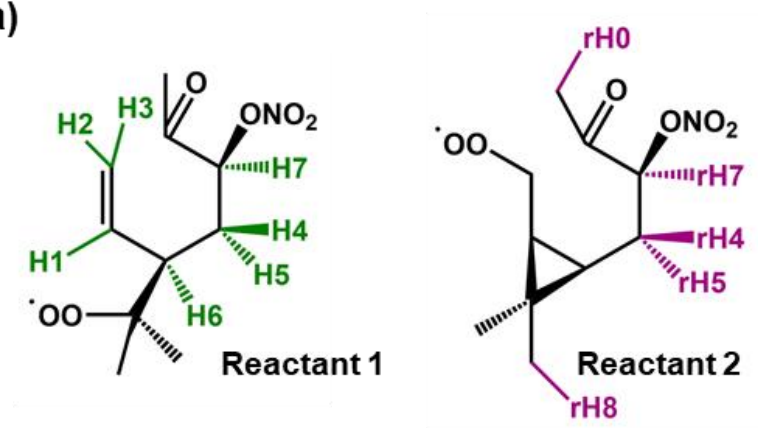

b)
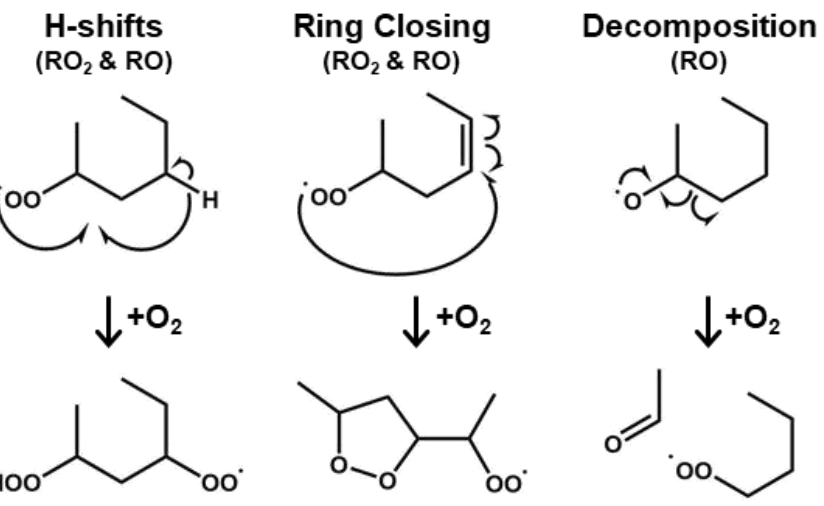

Figure 3. (a) Radical endpoints from $\Delta$-3-carene $+\mathrm{NO}_{3}$ mechanism in Kurtén et al., ${ }^{15}$ which comprise our reactants in this study, with hydrogens investigated in this study labeled and colorcoded to differentiate Reactant 1 and Reactant 2, and (b) schematic showing types of rearrangement reactions included in this study.

Accounting for all plausible hydrogen shifts, we compute forward reaction barrier heights and rate constants for all relevant reactions using quantum chemical methods that include coupledcluster energy corrections. For a few reactions, higher-level calculations were omitted as the barrier heights computed at a lower level of theory indicated that they would not be competitive. The resulting detailed mechanism could be applied to a kinetics model or used to develop a parameterization that can be implemented in regional or global models in order to improve estimates of SOA formation. 
Since our mechanism includes predictions of the distribution of product isomers, the results of this study are important for the interpretation of experimental data. The widespread application of chemical ionization mass spectrometry (CIMS) measurements to atmospheric chemistry has enabled characterization of the multitude of oxidized organic molecules resulting from complex chemistry. However, while some techniques can be applied to obtain chemical information beyond molecular formula, such as the use of multiple reagent ions selective toward different functional groups, ${ }^{18}$ mass spectra alone do not provide enough information to explain observed SOA formation. ${ }^{19}$ Two molecules with the same formula can vary by orders of magnitude in vapor pressure, depending on the identity and location of functional groups. In this study we compare our computational mechanism to laboratory measurements of the gas phase products of $\mathrm{NO}_{3}$ oxidation of $\Delta-3$-carene performed by CIMS using $\mathrm{NO}_{3}{ }^{-}$reagent ion. Since $\mathrm{NO}_{3}{ }^{-}$is selective toward highly oxidized organic species and only a small number of other molecules such as sulfuric acid, it is particularly suited to validate this mechanism focusing on autoxidation pathways. ${ }^{13,20,21}$

\section{METHODS}

\section{Computational}

The computational mechanism presented in this study was developed according to the methods described in Møller et al. ${ }^{22}$ and incorporating many of the modifications described in Kurtén et al. ${ }^{15}$ due to the size of the molecules studied here. Since our reactant $\mathrm{RO}_{2}$ structures are composed of 17 non-hydrogen atoms, use of the multi-conformer transition state theory (MCTST) framework was prohibitively expensive at any reasonable level of theory. We therefore made some additional modifications to the computational approach and calculated all rate constants using the lowest-conformer transition state theory (LC-TST) framework. ${ }^{22}$ These 
modifications lead to a much larger uncertainty for the absolute rate constants (approximately an order of magnitude) than the complete treatment prescribed in Møller et al. ${ }^{22}$ However, we expect the uncertainty from each modification to systematically bias absolute rate constants in the same direction for each reaction. For example, MC-TST accounts for the full population of conformers, so only including the lowest energy conformer by calculating rate constants with LC-TST will bias the absolute rate constants high. Likewise, Møller et al. ${ }^{22}$ showed that for these types of systems, increasing the level of theory decreases the calculated absolute rate constant. Therefore, this approach should provide reasonable relative rate constants, whichlikely overestimate the absolute rate constants, but are sufficient for comparative mechanism development. ${ }^{15}$ Additionally, due to the size of our reactants, and thus computational cost, we have chosen to investigate only the S-nitroxy stereoisomer of (+)- $\Delta-3$-carene since the $(+)-\Delta-3-$ carene enantiomer was used in the experimental portion of this study. Given that the stereocenter is far from the peroxy/alkoxy group and is freely able to rotate (since the 6-membered ring in $\Delta$ 3-carene has already opened for both of our reactants), we do not expect qualitative differences in the overall mechanism for the R-nitroxy stereoisomer.

Systematic conformer sampling for all reactants and products was performed with the Spartan'16 (Wavefunction, Inc.) software using the MMFF force field and ensuring the correct neutral charge was applied to all radical centers using the FFHINT keyword. ${ }^{22}$ MMFF conformer sampling for the transition state structures was performed using constrained optimizations, with the relevant bond lengths (and/or angles) constrained based on a B3LYP/6-31+G(d) transition state optimization of an arbitrary conformer using Gaussian 09 Rev. D. $01 .{ }^{23-25}$ Constraints for Hshift, C-C scission, and addition reactions are included in Table S1. In addition, partial bonds were drawn in Spartan to describe the breaking and/or forming bonds of the transition state. This 
improves the MMFF optimization of the conformer sampling and the resulting geometries are closer to the local energy minima than those from a conformer sampling where the bonds of the transition state are drawn according to either the reactant or the product. Following the MMFF conformer sampling for reactants, products, and transition states, we calculated B3LYP/6$31+\mathrm{G}(\mathrm{d})$ single point energies for all conformers and applied a $5 \mathrm{kcal} / \mathrm{mol}$ cutoff at this stage, as suggested in Moller et al. ${ }^{22}$ for larger molecules. The use of partial bonds was tested with an $\mathrm{H}-$ shift reaction between a hydroxy and a peroxy radical group of a model compound, and all of the unique transition state conformers (within $2 \mathrm{kcal} / \mathrm{mol}$ of the lowest energy conformer after the B3LYP/6-31+G(d) optimization) were found using a $5 \mathrm{kcal} / \mathrm{mol}$ energy cut-off after the B3LYP/6-31+G(d) single-point calculation. For reactants and products, we performed B3LYP/6-31+G(d) optimizations, and for transition states we performed B3LYP/6-31+G(d) constrained optimizations, using the constraints mentioned above, on all structures within 5 $\mathrm{kcal} / \mathrm{mol}$ of the lowest single point energy. For transition state structures, we performed full transition state optimizations with frequency calculations on unique conformers (determined by energy and dipole moment) following the constrained optimizations. Intrinsic reaction coordinate (IRC) calculations were then performed on the lowest-energy transition states at the B3LYP/6-31+G(d) level to verify that they connect the desired reactants and products. Due to the high cost of heavier calculations for molecules of this size, optimization and frequency calculations at the $\omega$ B97X-D/aug-cc-pVTZ level ${ }^{26-28}$ were only performed for the lowest-energy structures found in the B3LYP/6-31+G(d) optimizations.

While $\omega$ B97X-D yields reasonable geometries and frequencies, the single point energies should be corrected using a highly correlated wavefunction-based method, such as $\operatorname{CCSD}(\mathrm{T}){ }^{29}$ However, the computational cost of canonical coupled cluster scales exponentially with molecule 
size and therefore cannot be applied for the studied system sizes. Therefore, on top of the $\omega \mathrm{B} 97 \mathrm{X}-\mathrm{D} /$ aug-cc-pVTZ structures, DLPNO-CCSD(T) single point energy calculations were performed using ORCA 4.0.1.2 instead of the prohibitively expensive canonical $\operatorname{CCSD}(\mathrm{T})$ calculations. ${ }^{30,31}$ The DLPNO-CCSD(T) method scales nearly linearly with system size, while still keeping the accuracy of its canonical counterpart, and has therefore become a popular choice to correct electronic energies of large molecular systems. ${ }^{31,32}$ In order to check whether a singlereference method can be used for these systems, we tested both restricted open-shell and unrestricted Hartree-Fock (ROHF and UHF, respectively) reference wave functions for the DLPNO-CCSD(T) calculations, and also studied the $\mathrm{T} 1$ and $\mathrm{T} 2$ diagnostics, as well as the relative difference in DPLNO-CCSD and DLPNO-CCSD(T) total atomization energies. We found that ROHF and UHF wave functions yield similar DLPNO-CCSD(T) single point energies, with a mean absolute error of $0.2 \mathrm{kcal} / \mathrm{mol}$, and both $\mathrm{T} 1$ and $\mathrm{T} 2$ amplitudes and total atomization energies are within acceptable ranges (see Section S1), thus confirming that singlereference methods can safely be applied. The final single point energy corrections are therefore calculated using ROHF-DLPNO-CCSD(T)/aug-cc-pVTZ with tight pair natural orbital criteria. ${ }^{33}$

In the final LC-TST calculations, tunneling was treated using the Eckart model. ${ }^{34}$ This requires information on the energy differences (forward and reverse barriers) between the lowest-energy transition state, and the reactants and product connected by IRC paths to this transition state which may not be the lowest-energy reactants and products used in the overall LC-TST rate expression. Due to computational cost, the forward and reverse barriers needed for the tunneling calculation were estimated using a combination of approaches. Specifically, the $\omega$ B97X-D zeropoint corrected barriers (energy differences between the lowest-energy transition state and the lowest-energy reactant or product) was corrected by the B3LYP/6-31+G(d) energy difference 
between the lowest-energy conformer, and the conformer actually connected to the transition state via an IRC path.

\section{Experimental}

We conducted chamber experiments to validate the computational mechanism. Experiments were performed in a $560 \mathrm{~L}$ stainless steel chamber, described in detail in De Haan, et al., ${ }^{35}$ operating in flow-through mode with a 23 minute residence time. $\mathrm{NO}_{3}$ radical was formed in situ by combining $\mathrm{O}_{3}(\sim 370 \mathrm{ppb})$ with $\mathrm{NO}_{2}(\sim 200 \mathrm{ppb})$. Ozone was generated by irradiating purified air produced by a zero air generator (model 737-13, Aadco Instruments) with ultraviolet light produced by a PenRay lamp (model 97-0066-01, Analytik Jena). $\mathrm{NO}_{2}$ was provided by a commercially prepared gas cylinder (2.56 ppm in air, Airgas Corp.). The concentrations of these compounds in the chamber were monitored with commercial $\mathrm{O}_{3}$ (Model 106-L, 2B Technologies) and $\mathrm{NO}_{\mathrm{x}}$ (Model $405 \mathrm{~nm}, 2 \mathrm{~B}$ Technologies) analyzers. While we did not have $\mathrm{NO}_{3}$ radical or $\mathrm{N}_{2} \mathrm{O}_{5}$ measurements available, we estimated steady state concentrations of $\mathrm{N}_{2} \mathrm{O}_{5}$ $(\sim 50 \mathrm{ppb})$ and $\mathrm{NO}_{3}(\sim 0.6 \mathrm{ppb})$ using the home-built kinetics box model described in Draper et al. ${ }^{36}$ Once the oxidants reached steady state, $\Delta-3$-carene $(\sim 50 \mathrm{ppb})$ was added to the chamber for an approximate 1:1 $\Delta$-3-carene to $\mathrm{NO}_{3}$ ratio (including both $\mathrm{NO}_{3}$ and $\mathrm{N}_{2} \mathrm{O}_{5}$ ). The $\Delta$-3-carene source consisted of a home-prepared gas cylinder containing $23 \mathrm{ppm}$ of $(+)-\Delta-3$-carene $(>90 \%$ purity, TCI America.) in nitrogen.. Particle number-size distribution in the chamber was monitored with a Scanning Mobility Particle Sizer (SMPS) consisting of a Differential Mobility Analyzer (Model 3081, TSI, Inc.) and Ultrafine Condensation Particle Counter (Model 3020, TSI, Inc.). Gas-phase products, specifically the highly oxidized molecules that are the focus of the computational mechanism, were measured by chemical ionization mass spectrometry with the $\mathrm{NO}_{3}^{-}$reagent ion $\left(\mathrm{NO}_{3}^{-} \mathrm{CIMS}\right)$. This instrument employs a commercial CIMS inlet 
(Aerodyne, Corp.) based on the design by Eisele and Tanner ${ }^{37}$ coupled to a high resolution timeof-flight mass spectrometer (LTOF analyzer, Tofwerk AG). Kinetics modeling confirmed that $>98 \%$ of oxidation was $\mathrm{NO}_{3}$ radical-initiated, and comparison with an experiment conducted using only $\mathrm{O}_{3}$ and $\Delta-3$-carene confirmed that the product distribution for the $\mathrm{NO}_{3}$ experiment did not have any significant contribution from $\mathrm{O}_{3}+\Delta$-3-carene products (see Section S2).

$\mathrm{NO}_{3}{ }^{-}$CIMS mass spectra were analyzed in Igor Pro 6.3 (WaveMetrics, Inc.) using the Tofware analysis platform. Mass spectral data from $\mathrm{m} / \mathrm{z} 4$ to $\mathrm{m} / \mathrm{z} 800$ were processed, with most peaks $>1000$ ion counts identified and fit using high resolution peak fitting. Isotopes were constrained during peak fitting and accounted for when determining parent peak concentrations. The minimum detection limit is taken as 3 standard deviations above the baseline.

Log files from calculations and processed data from these experiments are publicly available and archived on the University of California Dash data publication service. ${ }^{38}$

\section{RESULTS AND DISCUSSION}

\section{Derived Reaction Mechanism}

A summary of the dominant pathways in the $\Delta$-3-carene $+\mathrm{NO}_{3}$ mechanism leading to the $3^{\text {rd }}$ generation of peroxy radicals is shown in Scheme 1 . The complete $\Delta$-3-carene $+\mathrm{NO}_{3}$ mechanism including minor channels and all reactions calculated in this study is included in Scheme S1. Black colored structures are reproduced from Kurtén et al., ${ }^{15}$ and green and purple structures differentiate pathways originating from the two reactant peroxy radicals (Reactant 1 and 2, respectively) studied in this work (Figure 3a, Scheme 1). The complete list of rate constants calculated in this study are compiled in Tables $1 \& 2$. While each generation of chemistry creates the potential for an exponentially increasing number of products, this mechanism demonstrates 
that this potential is tempered because each intermediate will often favor a specific reaction channel.

Scheme 1. Summary of dominant pathways in $\Delta$-3-carene $+\mathrm{NO}_{3}$ mechanism.*

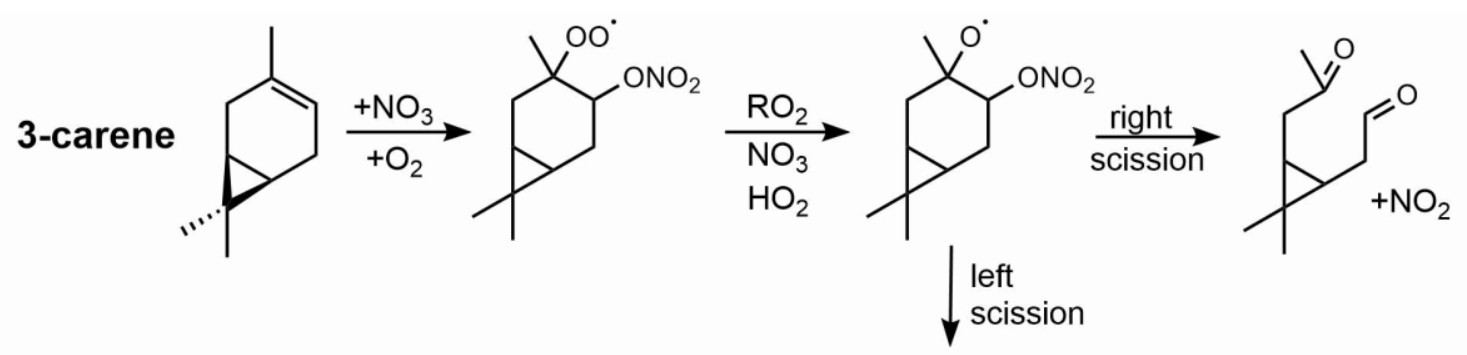

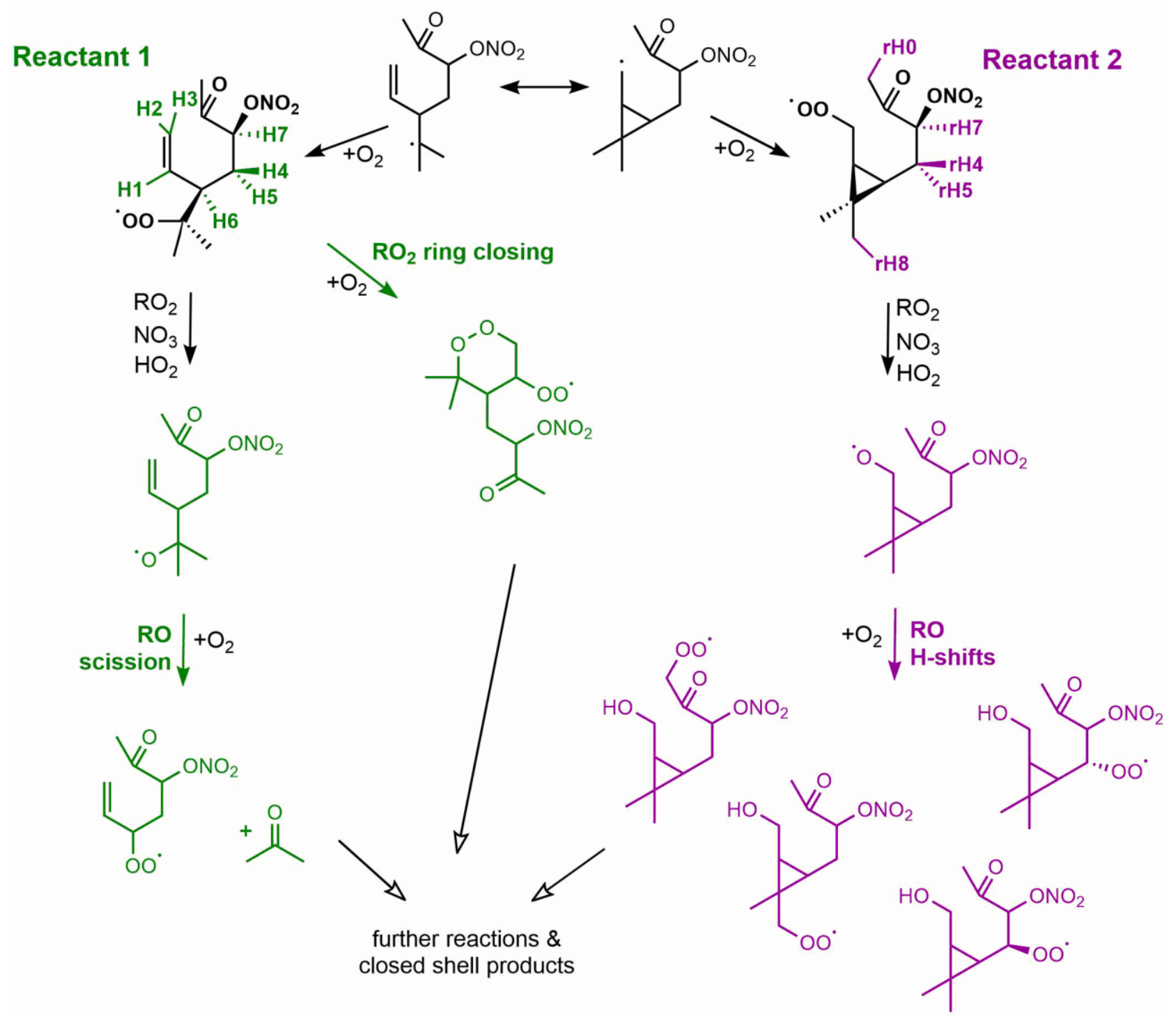

*Black structures and arrows indicate reactions inferred from literature, culminating in the radical endpoints in Kurtén et al., ${ }^{15}$ which serve as the "reactants" in this study. Green and purple 
structures and arrows indicate reactions calculated in this study originating from Reactant 1 and Reactant 2, respectively. For complete mechanism, including all pathways assessed in this study, refer to Scheme S1.

Table 1. Barriers ( $E_{b}$, zero-point corrected transition state - reactant electronic energy differences) and lowest-conformer transition state theory (LC-TST) rate constants (298.15 K) calculated for $\mathrm{RO}_{2} \mathrm{H}$-shifts and $\mathrm{RO}_{2}$ ring closing. Calculations were performed at the $\omega \mathrm{B} 97 \mathrm{X}$ D/aug-cc-pVTZ level with single point energy corrections at the ROHF-DLPNO-CCSD(T)/augcc-pVTZ level.

\begin{tabular}{|l|c|c|}
\hline \multicolumn{2}{|c|}{$\mathrm{RO}_{2} \mathrm{H}$-shifts (R8 in Table S4) } \\
\hline Reaction Description & $\mathrm{E}_{\mathrm{b}}\left(\mathrm{kcal} \mathrm{\textrm {mol } ^ { - 1 } )}\right.$ \\
\hline Reactant 1 H1 & 66.0 & $5.3 \times 10^{-9}$ \\
\hline Reactant 1 H2 & $5.5 \times 10^{-30}$ \\
\hline Reactant 1 H4 & 34.3 & $6.7 \times 10^{-13}$ \\
\hline Reactant 1 H5 & 26.8 & $2.9 \times 10^{-7}$ \\
\hline Reactant 1 H6 & 25.7 & $5.8 \times 10^{-6}$ \\
\hline Reactant 1 H7 & 30.7 & $4.2 \times 10^{-6}$ \\
\hline Reactant 2 rH4 & 21.7 & $8.0 \times 10^{-2}$ \\
\hline Reactant 2 rH5 & 23.2 & $6.4 \times 10^{-4}$ \\
\hline Reactant 2 rH7 & 24.2 & $1.9 \times 10^{-5}$ \\
\hline \multicolumn{2}{|c|}{ RO Ring Closing (R9 in Table S4) } \\
\hline Reactant 1 6-membered endoperoxide & 18.1 & $4.7 \times 10^{-2}$ \\
\hline
\end{tabular}

\section{$\mathrm{RO}_{2}$ fate}

Starting with Reactant 1 and Reactant 2, we began by surveying the pathways available to these $\mathrm{RO}_{2}$ radicals. Since our mechanism explicitly calculates only the unimolecular reaction rate 
constants, we have estimated the pseudo-1st order rate constant for bimolecular reactions to be of order $10^{-2} \mathrm{~s}^{-1}$ based on literature rate constants $\left(\mathrm{k}_{\mathrm{RO} 2+\mathrm{RO} 2} \sim 10^{-12} \mathrm{~cm}^{3} \mathrm{molec}^{-1} \mathrm{~s}^{-1}\right.$ and $\mathrm{k}_{\mathrm{RO} 2+\mathrm{NO} 3}=2 \times 10^{-12} \mathrm{~cm}^{3}$ molec $\left.^{-1} \mathrm{~s}^{-1}\right)^{9,21}$ and radical concentrations representative of the chamber experiments in this study $\left(\left[\mathrm{RO}_{2}\right] \approx 0.7 \mathrm{ppb},\left[\mathrm{NO}_{3}\right] \approx 0.4 \mathrm{ppb}\right)$ (see Figure $\mathrm{S} 4$ ). Incidentally, this is a reasonable estimate under certain ambient conditions as well since $\mathrm{HO}_{2}$ is a significant bimolecular sink for $\mathrm{RO}_{2}$ in the atmosphere (assuming a "typical" ambient $\left[\mathrm{HO}_{2}\right] \sim 100$ ppt and $\left.\mathrm{k}_{\mathrm{RO} 2+\mathrm{HO} 2}=2 \times 10^{-11} \mathrm{~cm}^{3} \operatorname{molec}^{-1} \mathrm{~s}^{-1}\right),{ }^{9,39}$ but $\left[\mathrm{HO}_{2}\right]$ is assumed to be negligible in these chamber experiments. Therefore, to be competitive, $\mathrm{RO}_{2}$ unimolecular rate constants must be comparable to or faster than $10^{-2} \mathrm{~s}^{-1}$.

\section{$\mathrm{RO}_{2}$ H-shifts}

Hydrogen shifts were calculated for all unique hydrogens greater than a 1,4-H-shift apart, with the exception of methyl hydrogens, which have been shown to be slow in other studies, ${ }^{11}$ and hydrogens on the strained 3-membered ring, which were shown in Kurtén et al. ${ }^{15}$ to lead to a highly unstable alkyl radical. This includes all hydrogens labeled in Figure 3a except for rH0 and rH8. The fastest $\mathrm{RO}_{2} \mathrm{H}$-shifts in each reactant were for the hydrogen $\alpha$ to the $-\mathrm{ONO}_{2}$ group and $\beta$ to the $=\mathrm{O}$ group $(\mathrm{H} 7$ and $\mathrm{rH} 7)$. These $\mathrm{H}$-shifts are of order $10^{-2} \mathrm{~s}^{-1}$ and therefore are competitive with bimolecular reaction. However, the alkyl radical at this site leads to rapid loss of $\mathrm{NO}_{2}$ and termination of the radical as a carbonyl group, so while this pathway contributes to the final product distribution, it does not lead to further oxidation. ${ }^{11}$ The remaining $\mathrm{RO}_{2} \mathrm{H}$-shifts range from approximately $10^{-13}-10^{-4} \mathrm{~s}^{-1}$ and therefore are too slow to contribute significantly to the final product distribution.

While the majority of these rate constants are too slow to be competitive, it is instructive to look at which of these H-shifts are more favorable than others for this complex, multifunctional 
molecule. Although a SAR does not currently exist for $\mathrm{RO}_{2} \mathrm{H}$-shifts, Otkjaer et al. ${ }^{11}$ tested the effects of different substituents and transition state ring size for $\mathrm{RO}_{2} \mathrm{H}$-shifts. Considering only the substituents and transition state ring sizes relevant for this study, we would predict that the $\mathrm{C}=\mathrm{O}$ group would increase $\mathrm{H}$-shift rates and the $-\mathrm{ONO}_{2}$ group is unlikely to have any significant effect. With respect to transition state ring size, the slowest reactions would be 1,4 $\mathrm{H}$-shifts, and 1,6 H-shifts are likely to be the fastest but comparable to 1,5 and 1,7 H-shifts. Additionally, $\mathrm{H}-$ shifts are faster on tertiary carbons and slower on primary carbons. ${ }^{11}$ Our results are qualitatively consistent with the trends described in Otkjaer et al. ${ }^{11}$ and references therein. The two fastest $\mathrm{H}-$ shifts (H7 and rH7), which are somewhat competitive in our mechanism, are $\alpha$ to a nitrate ($\mathrm{ONO}_{2}$ ) group and $\beta$ to a carbonyl $(=\mathrm{O})$, and we attribute the fast rate to the proximity to the carbonyl. After $\mathrm{H} 7$ and $\mathrm{rH} 7$, the fastest $\mathrm{H}$-shifts were the 1,6-H-shifts from the secondary carbon, $\beta$ to the nitrate group in Reactant $2(\mathrm{rH} 4, \mathrm{rH} 5)$. Since we do not expect the nitrate group to have a significant effect, these two hydrogens provide a good baseline of sorts for a molecule of this size, where additional substituents or more strained transition states will provide an enhancement or depression of the H-shift rate. The H-shifts of these corresponding hydrogens in Reactant 1 $(\mathrm{H} 4, \mathrm{H} 5)$, are 1-2 orders of magnitude slower, perhaps because they are 1,5-H-shifts, which is a slightly more strained transition state. The hydrogen on the tertiary carbon in Reactant 1 (H6) has a rate constant comparable to $\mathrm{H} 4$ and $\mathrm{H} 5$, likely due to a net cancellation of the enhancement of the more weakly bound tertiary hydrogen by the more highly strained transition state of the 1,4H-shift. Overall, the H-shifts from the double bonded carbons (H1, H2, H3) are the least favorable of the ones tested, which is not surprising since the vinyl $\mathrm{C}-\mathrm{H}$ bonds are comparatively strong.

\section{$\mathrm{RO}_{2}$ Ring Closing}


Reactant 1 arises from the opening of the 3-membered ring, which forms a new double bond. We therefore tested whether the peroxy radical is able to add to the double bond, forming a 6membered endoperoxide ring. While it is also possible to add to the other side of the double bond, forming a 5-membered ring, this scenario results in a smaller ring and a primary alkyl radical, so we would expect this pathway to be slower than formation of the 6-membered endoperoxide. This type of endoperoxide formation reaction has been suggested to occur fairly rapidly (up to $\sim 1 \mathrm{~s}^{-1}$ ) in the ozonolysis of a cyclodiene as well as in the photooxidation of $\alpha$ pinene. ${ }^{40,41}$ As with the more well-known $\mathrm{H}$-shift reactions, this reaction results in a similar autoxidation process, with $\mathrm{O}_{2}$ adding to the newly formed alkyl radical. We calculated this ring closing reaction to have a rate constant of approximately $5 \times 10^{-2} \mathrm{~s}^{-1}$ for Reactant 1 , making it competitive with bimolecular reaction, and consistent with the $\alpha$-pinene endoperoxide formation reactions in $\mathrm{Xu}$ et al. ${ }^{41}$ that result in secondary radicals, which are somewhat slower than those leading to tertiary radicals.

\section{RO fate}

Based on the calculated rate constants described above for $\mathrm{RO}_{2}$ unimolecular reactions, we expect that the product distribution from Reactant 1 will have some contribution from the endoperoxide channel as well as some closed-shell $\mathrm{C}_{10} \mathrm{H}_{16} \mathrm{O}_{4}$ from the $\mathrm{H} 7 \mathrm{H}$-shift, but a significant amount of these $\mathrm{RO}_{2}$ will undergo bimolecular reaction and become $\mathrm{RO}$ radicals. For Reactant 2, which does not have an endoperoxide channel available to it, some $\mathrm{C}_{10} \mathrm{H}_{16} \mathrm{O}_{4}$ from the $\mathrm{rH} 7 \mathrm{H}$-shift will form, and the significant remainder will be converted to RO by bimolecular reactions. We therefore assess the unimolecular reaction pathways available to these alkoxy radical products, including H-shifts, decomposition, and ring closing. Since published SARs are

available for both alkoxy H-shifts and alkoxy bond scissions, ${ }^{16,17}$ we started by implementing 
those to estimate which RO pathways are likely to be competitive for the Reactant 1 and Reactant 2 RO radicals.

Alkoxy scission reactions are influenced most strongly by the substituents on the $\alpha$ and $\beta$ carbons, so any further substituents can be neglected when applying the SAR. ${ }^{16}$ The alkoxy radical formed from Reactant 1 has two alkyl groups on each the $\alpha$ and $\beta$ carbons, which reduce the overall SAR-predicted reaction barrier to $6.5 \mathrm{kcal} / \mathrm{mol}$, compared to the $17.9 \mathrm{kcal} / \mathrm{mol}$ "baseline" forward barrier for the unsubstituted $\mathrm{RO} \mathrm{CH}_{3} \mathrm{CH}_{2} \mathrm{O}$. Reactant 2, on the other hand, has no substituents on the $\alpha$ carbon and a cyclopropyl ring on the $\beta$ carbon. Scission of a C-C bond adjacent to a cyclopropyl ring leads to an alkyl radical on a highly strained ring, so this substituent results in an increase of the overall reaction barrier to $20.3 \mathrm{kcal} / \mathrm{mol}$. H-shift favorability relies heavily on the structure of a molecule as a whole, since H-shifts can take place between carbons at different distances from the radical center (span) and are impacted by the location of functional groups (substituents). ${ }^{17}$ Due to the wider range of span and substituent permutations, this SAR is less complete, for example lacking effects from $-\mathrm{ONO}_{2}$ groups, so we calculated these SAR-predicted rate constants assuming missing substituents would have a negligible effect. SAR-predicted forward energy barriers for alkoxy scission reactions and rate constants for alkoxy $\mathrm{H}$-shift reactions are included in Table 2.

Table 2. Barriers (Eb, zero-point corrected transition state - reactant electronic energy differences) and lowest-conformer transition state theory (LC-TST) rate constants (298.15 K) calculated for RO H-shifts, ring closing, and decomposition for alkoxy radicals derived from Reactant 1 and Reactant 2. Calculations were performed at the $\omega B$ 97X-D/aug-cc-pVTZ level 
with single point energy corrections at the ROHF-DLPNO-CCSD(T)/aug-cc-pVTZ level. SAR predictions of $\mathrm{E}_{\mathrm{b}}$ and $\mathrm{k}$ are included when available. ${ }^{16,17}$

\begin{tabular}{|c|c|c|c|}
\hline Reaction Description & $\mathrm{E}_{\mathrm{b}}\left(\mathrm{kcal} \mathrm{mol}^{-1}\right)$ & $\mathrm{k}\left(\mathrm{s}^{-1}\right)$ & SAR prediction \\
\hline \multicolumn{3}{|c|}{ RO H-shifts (R10 in Table S4) } & SAR predicted $\mathrm{k}\left(\mathrm{s}^{-1}\right)$ \\
\hline Reactant $1 \mathrm{H} 0$ & -- & -- & $0.46-17^{*}$ \\
\hline Reactant $1 \mathrm{H} 4$ & -- & -- & 0.24 \\
\hline Reactant $1 \mathrm{H} 5$ & -- & -- & 0.24 \\
\hline Reactant $1 \mathrm{H} 7$ & -- & -- & $1.1 \times 10^{7}$ \\
\hline Reactant $2 \mathrm{rH} 0$ & 11.8 & $3.0 \times 10^{4}$ & $3.4 \times 10^{-2}-0.51^{*}$ \\
\hline Reactant 2 rH4 & 8.4 & $1.8 \times 10^{7}$ & $3.3 \times 10^{6}$ \\
\hline Reactant 2 rH5 & 9.5 & $1.6 \times 10^{6}$ & $3.3 \times 10^{6}$ \\
\hline Reactant $2 \mathrm{rH} 7$ & 8.8 & $3.7 \times 10^{6}$ & $2.0 \times 10^{6}$ \\
\hline Reactant 2 rH8 & 8.3 & $2.3 \times 10^{7}$ & $3.2 \times 10^{5}$ \\
\hline \multicolumn{4}{|c|}{ RO Addition** (R12 in Table S4) } \\
\hline Reactant 1 4-membered endo-ether & 12.3 & -- & -- \\
\hline Reactant 15 -membered endo-ether & 15.7 & -- & -- \\
\hline \multicolumn{3}{|c|}{ RO decomposition (R11 in Table S4) } & $\begin{array}{l}\text { SAR predicted } \mathrm{E}_{\mathrm{b}} \\
(\mathrm{kcal} / \mathrm{mol})\end{array}$ \\
\hline Reactant 1 C-C scission & 7.1 & $6.6 \times 10^{7}$ & 6.5 \\
\hline Reactant 2 C-C scission & -- & -- & 20.3 \\
\hline
\end{tabular}

*Range of SAR-predicted $\mathrm{k}$ values come from structures with H-shifts not easily described by the SAR and therefore calculated using two different assumptions.

**Note: these barriers were calculated for an arbitrary conformer at the B3LYP/6-31+G(d) level to confirm that the reaction would be slow relative to R1 C-C scission and thus unlikely to contribute to the final product distribution. 
In spite of the increased uncertainty for the SAR-predicted H-shift rate constants due to missing substituents, the large predicted differences in barrier heights between the Reactant 1 and Reactant 2 alkoxy scission reactions makes it clear which pathway(s) will be favored by each reactant. We predict an extremely low barrier $(6.5 \mathrm{kcal} / \mathrm{mol})$ for the Reactant $1 \mathrm{RO}$ scission, which we estimate to correspond to a rate constant of $\sim 1 \times 10^{8} \mathrm{~s}^{-1}$ from similar alkoxy scission barriers in Kurtén et al. ${ }^{15}$ SAR-predicted rate constants range from $10^{-2}-20 \mathrm{~s}^{-1}$ for most available $\mathrm{H}$-shifts in the Reactant $1 \mathrm{RO}$, with one notable exception. Following the qualitative trend of the $\mathrm{RO}_{2}$ radicals, the hydrogen $\alpha$ to the $-\mathrm{ONO}_{2}$ group and $\beta$ to the $=\mathrm{O}$ group $(\mathrm{H} 7)$ is predicted to have a rate constant of order $10^{7} \mathrm{~s}^{-1}$, which will be competitive with RO scission for this reactant. This $\mathrm{H}$-shift leads to rapid loss of $\mathrm{NO}_{2}$ and termination of the radical to closed-shell $\mathrm{C}_{10} \mathrm{H}_{16} \mathrm{O}_{3}$, whereas the $\mathrm{RO}$ scission pathway will lead to continued radical propagation reactions, so we focus on the RO scission pathway for Reactant 1 . In contrast, the predicted barrier for alkoxy scission for the Reactant $2 \mathrm{RO}$ is quite high $(20.3 \mathrm{kcal} / \mathrm{mol})$ due to formation of a radical on the strained cyclopropyl ring. We can estimate this barrier to correspond to a rate constant of $<10^{-2} \mathrm{~s}^{-1}$ using the $\mathrm{RO}_{2}$ ring closing barrier/rate constant from Table 1 as an upper limit since neither the scission or ring closing reaction require significant tunneling corrections, unlike the $\mathrm{H}$-shift reactions. Since SAR-predicted H-shift rate constants range from $10^{-2}-10^{6} \mathrm{~s}^{-1}$, with the majority of hydrogens having rate constants above $10^{5} \mathrm{~s}^{-1}$, we can infer that the Reactant 2 RO will favor $\mathrm{H}$-shifts over scission reactions.

LC-TST calculated rate constants for alkoxy reactions are shown in Table 2. Alkoxy scission in Reactant 1 occurs at a calculated rate of $7 \times 10^{7} \mathrm{~s}^{-1}$, confirming that H-shifts (except for H7) should be negligible in comparison. Rate constants for H-shift reactions in Reactant 2 alkoxy radicals were calculated for all hydrogens labeled in Figure 3a, this time also assessing whether 
methyl hydrogens with rate enhancing substituents at $\beta$ positions ( $\mathrm{rH} 0$ and $\mathrm{rH} 8$ ) might also be competitive, since $\mathrm{RO}$ chemistry is typically much faster than $\mathrm{RO}_{2}$ chemistry. Calculated rate constants range from $3 \times 10^{4}-2 \times 10^{7} \mathrm{~s}^{-1}$. As expected from the trends observed in the $\mathrm{RO}_{2} \mathrm{H}-$ shifts, $\mathrm{rH} 4, \mathrm{rH} 5$, and $\mathrm{rH} 7$ are among the fastest, with the methyl hydrogen $\mathrm{rH} 0$ being the slowest. Unexpectedly, however, the fastest RO H-shift is from the methyl hydrogen rH8, likely due to a combination of a very favorable transition state geometry, as well as some additional stabilization due to the strained ring $\beta$ to the subsequent alkyl radical. Barrier heights were also calculated for RO addition over the double bond in Reactant 1, but these calculations indicated that this ether-forming reaction is not competitive with the extremely fast RO scission or H-shift reactions. Since our calculated rate constants span many orders of magnitude, it is clear which pathways will dominate, but we note that the barriers for any of the fast RO reactions are quite low and therefore these rate constants calculated using transition state theory will have even larger absolute uncertainties than for the higher barrier $\mathrm{RO}_{2}$ reactions.

The LC-TST calculations confirmed the qualitative results of the SARs, with two H-shifts being 2-6 orders of magnitude faster than predicted by the SAR. The rate constants that deviated most significantly from the SAR predictions were those from methyl hydrogens that were seemingly better represented by the span and substituents included in the SAR. However, these deviations may have come from unincluded substituents like the cyclopropyl ring (rH8) and the fact that assumptions had to be made to combine substituent effects of the $-\mathrm{C}=\mathrm{O}$ group at a 1,7 span ( $\mathrm{rH} 0)$. The SAR predicted rate constants well for the H-shifts where we had to assume that e.g. an $-\mathrm{ONO}_{2}$ group has a negligible effect.

\section{Computational Summary}


From these results, it is evident that three dominant radical pathways emerge from $\Delta$-3-carene $+\mathrm{NO}_{3} 2^{\text {nd }}$ generation $\mathrm{RO}_{2}$ chemistry. Reactant 1 leads to radical products following $\mathrm{RO}_{2}$ addition to an internal double bond, as well as alkoxy radicals from bimolecular reaction, which subsequently undergo scission reactions leading predominantly to easily identifiable $\mathrm{C}_{7}$ radical intermediates. Reactant 2 proceeds straight to alkoxy radicals from bimolecular reaction, which predominantly undergo $\mathrm{H}$-shift reactions, retaining their $\mathrm{C}_{10}$ backbone. These pathways are summarized in Scheme 1, and thus a complete mechanism through $2^{\text {nd }}$ generation products emerges that combines these results with those of Kurtén et al. ${ }^{15}$, along with inferred closed-shell products based on known oxidation chemistry (Scheme S1). Even though assessing the $3^{\text {rd }}$ generation of unimolecular chemistry for this system is computationally unfeasible, understanding the $2^{\text {nd }}$ generation of chemistry helps us understand the balance between bimolecular and unimolecular reactions in the atmosphere, which is a crucial link between known oxidation chemistry and experimental results.

\section{Chamber experiments}

Chamber experiments focused specifically on gas-phase $\mathrm{NO}_{3}{ }^{-} \mathrm{CIMS}$ measurements to provide comparative measurements of the highly oxidized products formed from $\mathrm{NO}_{3}$ radical oxidation of $\Delta$-3-carene. SMPS measurements showed new particle formation and subsequent particle growth during these experiments (see Figure S2), but particle-phase composition was outside the scope of this study. The complete table of identified products is included in Table S7, and Figures $4 \mathrm{a}$ and $4 \mathrm{c}$ show a mass spectrum averaged over the duration of the experiment with structures assigned to the highest intensity peaks. When comparing a CIMS spectrum to the proposed mechanism, we must take into consideration which molecules will be detectable by the selected reagent ion chemistry. $\mathrm{NO}_{3}{ }^{-} \mathrm{CIMS}$ will only detect molecules that have a larger binding 
energy with $\mathrm{NO}_{3}{ }^{-}$than the binding energy of $\mathrm{NO}_{3}{ }^{-}$with $\mathrm{HNO}_{3}$. Hyttinen et al. ${ }^{20}$ showed that $\mathrm{C}_{6}$ molecules containing at least two hydrogen bond (H-bond) donors will bind with $\mathrm{NO}_{3}{ }^{-}$, and are thus detectable by $\mathrm{NO}_{3}{ }^{-}$CIMS, with increasing oxidation generally leading to stronger binding. While the products observed in this study seem to have a high enough oxidation state, many of these oxygens come from nitrate or carbonyl functionalities, so some pathways require multiple generations of chemistry to get even one H-bond donor. To ensure that we were assigning detectable structures to our $\mathrm{NO}_{3}{ }^{-} \mathrm{CIMS}$ spectrum, we performed ion-clustering calculations on two expected products to investigate whether binding to $\mathrm{NO}_{3}{ }^{-}$is, in fact, favorable. These results are shown in Section S3. For the highly oxidized compounds in this study $\left(>\mathrm{O}_{7}\right)$, our results indicate that a single $\mathrm{H}$-bond donor is sufficient to bind with $\mathrm{NO}_{3}{ }^{-}$. Interestingly, despite not containing any $\mathrm{H}$-bond donors, the dipole-dipole interactions in the $\mathrm{RO}_{2}$ formed following $\mathrm{RO}_{2}$ ring closing from Reactant 1 are sufficient to make clustering with $\mathrm{NO}_{3}{ }^{-}$competitive with $\mathrm{HNO}_{3}\left(\mathrm{NO}_{3}^{-}\right)$cluster formation.
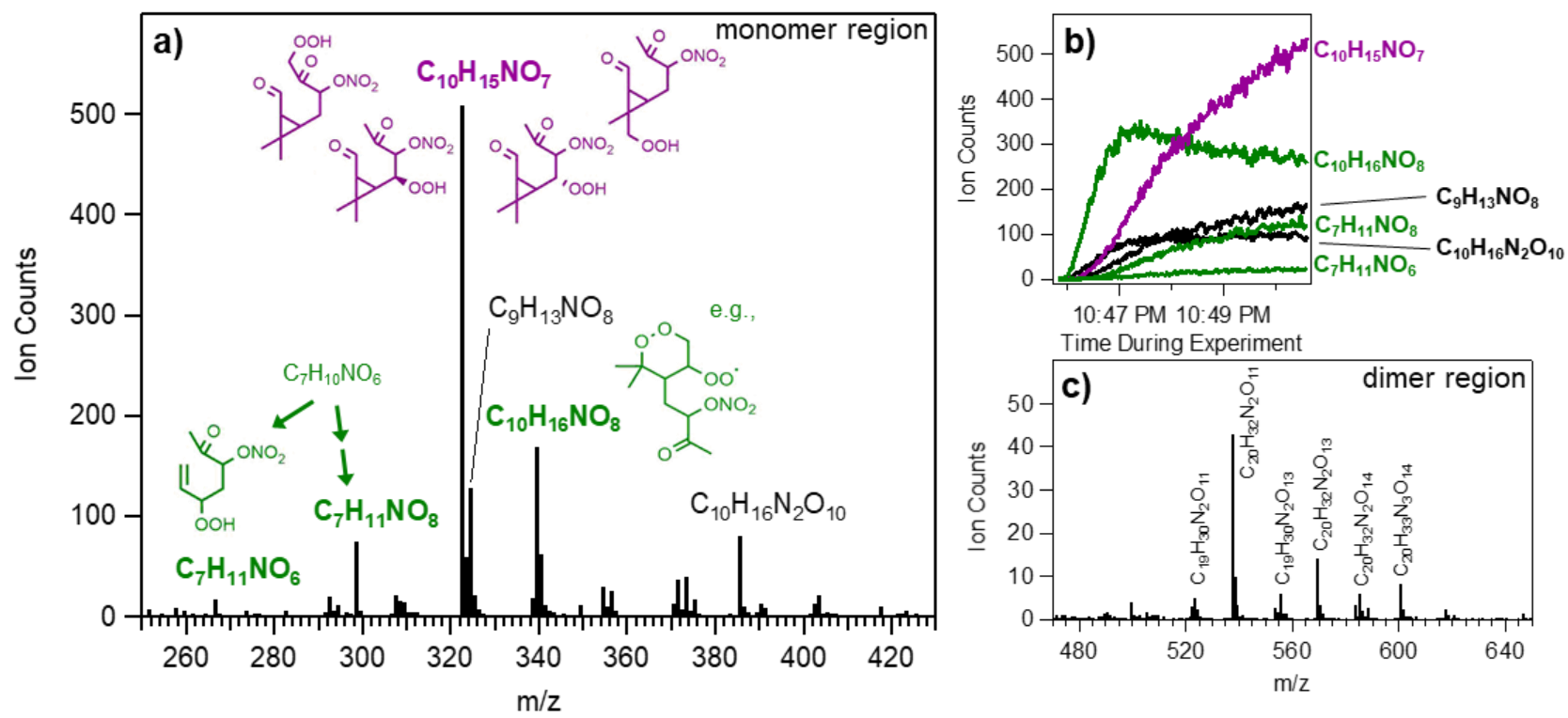

Figure 4. (a) Monomer region of average mass spectrum from $\Delta$-3-carene $+\mathrm{NO}_{3}$ chamber experiment with structures for highest intensity peaks consistent with computational mechanism. 
$\mathrm{M} / \mathrm{z}$ values reflect $\mathrm{NO}_{3}{ }^{-}$adducts $\left(\mathrm{M}\left(\mathrm{NO}_{3}{ }^{-}\right)\right)$as detected, and labeled peaks reflect the product (M) alone. $\mathrm{C}_{7} \mathrm{H}_{11} \mathrm{NO}_{8}$ was not included in the mechanism in this study, but is expected to be a $3^{\text {rd }}$ generation product related to $\mathrm{C}_{7} \mathrm{H}_{10} \mathrm{NO}_{6}$. (b) Time series of the five highest intensity observed peaks as well as $\mathrm{C}_{7} \mathrm{H}_{11} \mathrm{NO}_{6}$ since it is the closed-shell product of one of our explicitly calculated intermediates. (c) Dimer region of mass spectrum with highest intensity peak formulas labeled.

Figure 4a shows that three of the five highest intensity observed peaks are consistent with products of the dominant reaction pathways identified in our computational mechanism. The highest intensity peak, $\mathrm{C}_{10} \mathrm{H}_{15} \mathrm{NO}_{7}$ most likely arises from Reactant 2 undergoing bimolecular reaction to produce RO, which undergoes one of several possible $\mathrm{H}$-shifts with subsequent $\mathrm{O}_{2}$ addition. We then assume that the $\alpha-\mathrm{OH} \mathrm{H}$-shift available to this new $\mathrm{RO}_{2}$ will be fast compared to other pathways and result in closed-shell $\mathrm{C}_{10} \mathrm{H}_{15} \mathrm{NO}_{7}$ by reaction with $\mathrm{O}_{2}$ and loss of $\mathrm{HO}_{2}$. The second highest intensity peak, $\mathrm{C}_{10} \mathrm{H}_{16} \mathrm{NO}_{8}$ must be a radical species given the even number of hydrogens and one nitrogen. This formula is consistent with the $\mathrm{RO}_{2}$ radical formed from the $\mathrm{RO}_{2}$ ring closing of Reactant 1 and subsequent $\mathrm{O}_{2}$ addition. It is somewhat surprising that we would measure this particular $\mathrm{RO}_{2}$ at such high intensity given that, as a radical intermediate, it is likely to react away relatively quickly. Additionally, the clustering calculations described above indicate $\mathrm{NO}_{3}{ }^{-}$clustering with this radical may be competitive with $\mathrm{HNO}_{3}$, but not strongly, so we would expect to detect this species with lower sensitivity than others with more favorable interactions relative to $\mathrm{HNO}_{3}$. Looking at the time series of the species highlighted in Figure $4 \mathrm{~b}$, however, we see this ion appears earlier than any of the products postulated to come from RO unimolecular reactions, consistent with the fact that it would form directly from unimolecular reactions of Reactant 1 or 2. 
Some products remain unexplained or unexplored by the proposed mechanism. For example, formation of a $\mathrm{C}_{9}$ species is difficult to understand from the chemical pathways considered. Formation of dinitrate species (e.g. $\mathrm{C}_{10} \mathrm{H}_{16} \mathrm{~N}_{2} \mathrm{O}_{10}$ ) was not explored computationally, but given that Reactant 1 and many of its subsequent products and intermediates contain a double bond, these are easily justified by a second $\mathrm{NO}_{3}$ addition reaction. Dimer formation (for example via $\mathrm{RO}_{2}+\mathrm{RO}_{2}$ reactions) was outside the scope of this study, but as seen in Figure 4c, most observed dimers are consistent with predicted monomer building blocks.

\section{Implications for SOA Formation}

The derived mechanism and experimental results in this study describe autoxidation processes and products in the gas-phase up to the formation of $2^{\text {nd }}$ generation products. This part of the mechanism provides valuable insights into the SOA forming potential of $\Delta$-3-carene $+\mathrm{NO}_{3}$ and can be extrapolated to some of the other monoterpenes that form $\mathrm{SOA}$ from $\mathrm{NO}_{3}$ oxidation. To start, we observe a number of dimer species, which have been correlated to new particle

formation rates for other chemical systems ${ }^{42,43}$ Since the dimers in our study are also likely to be the lowest volatility products, we assume that these are the products linked most strongly to initial particle formation and the earliest stages of growth. We have estimated vapor pressures for many of our expected closed-shell products using the SIMPOL.1 group contribution method ${ }^{44}$ and tabulated these in Chart S1. For the monomer products with known structures, vapor pressures at $298 \mathrm{~K}$ range from $1.6 \times 10^{-2}$ torr for caronaldehyde $\left(\mathrm{C}_{10} \mathrm{H}_{16} \mathrm{O}_{2}\right)$ to $5.1 \times 10^{-8}$ torr for $\mathrm{C}_{10} \mathrm{H}_{17} \mathrm{NO}_{7}$ multifunctional hydroperoxides. If we consider "semi-volatile" vapor pressures (defined liberally, encompassing volatility ranges between primarily gas-phase and primarily condensed-phase) as ranging from $7.6 \times 10^{-2}-7.6 \times 10^{-9}$ torr, ${ }^{45}$ nearly all products in this mechanism would be expected to be able to partition into the particle-phase, at least to some 
degree. Caronaldehyde, analogous to pinonaldehyde in the $\alpha$-pinene $+\mathrm{NO}_{3}$ system, is one of the few products that is too volatile to contribute significantly to the particle-phase under atmospherically-relevant aerosol mass loadings, ${ }^{46}$ whereas many of the products arising from the unimolecular pathways explored in this study have estimated vapor pressures on the very low end of our defined semi-volatile range, and therefore will partition heavily into the particlephase. The abundance of low volatility, highly oxidized monomers is consistent with observations of relatively small particle number concentrations but fast growth rates in other chamber experiments probing this chemistry. ${ }^{7,36}$ 


\section{CONCLUSIONS}

In this work, we have expanded upon the known $1^{\text {st }}$ generation chemistry of $\Delta$-3-carene $+\mathrm{NO}_{3}$ to include five different unimolecular reactions available to $2^{\text {nd }}$ generation $\mathrm{RO}_{2}$ radicals. In doing so, we have also assessed some of the structural features hindering and enhancing unimolecular reactions for $\mathrm{C}_{10}$ multifunctional molecules. In contrast to some of the chemical systems identified in recent years to undergo rapid and accelerating $\mathrm{H}$-shift and autoxidation reactions leading to very highly oxidized and often extremely low volatility products, ${ }^{10,13} \mathrm{NO}_{3}+$ monoterpene oxidation products have a much more modest and balanced contribution from both unimolecular and bimolecular radical reactions. This is likely due to the combination of a strained secondary ring, which inhibits $\mathrm{H}$-abstraction or alkyl radical-forming reactions on carbons within that ring, as well as the $-\mathrm{ONO}_{2}$ group, which does not strongly enhance unimolecular reactions and is also prone to decomposing to $\mathrm{NO}_{2}$ and a closed-shell product, thus terminating radical propagation. However, we also observed an unexpected enhancement of the RO H-shift rate from a methyl $\mathrm{H} \beta$ to the strained cyclopropyl ring. Understanding this balance between gas-phase bimolecular and unimolecular oxidation pathways is valuable for many chemical systems that, like $\Delta-3$-carene $+\mathrm{NO}_{3}$, produce $\mathrm{SOA}$ but do not necessarily have dominant autoxidation pathways available, whether due to structural features or due to decreased $\mathrm{RO}_{2}$ lifetimes in more polluted environments. 


\section{ASSOCIATED CONTENT}

\section{Supporting Information.}

The supporting information file is available free of charge and contains the following information:

Constraints applied to B3LYP/6-31+G* constrained optimizations of transition states for each type of reaction; The usage of single-reference ROHF-DLPNO-CCSD(T) method; T1 values, largest T2 amplitudes, $\triangle \mathrm{EROHF-UHF} \mathrm{(in} \mathrm{kcal} / \mathrm{mol}$ ) and the triples correction percentage from the atomization energy; Barrier heights and LC-TST rate constants calculated at different levels of theory; Forward and reverse IRC barriers used to calculate the Eckart Tunneling Coefficient; Particle size distribution during an $\mathrm{NO}_{3}+\Delta$-3-carene experiment; Kinetics model prediction of trace gas evolution during an $\mathrm{NO}_{3}+\Delta$-3-carene experiment; Additional kinetics modeling results showing that $>98 \%$ of $\Delta$-3-carene was oxidized by NO3 during NO3 experiments; Comparison of $\mathrm{NO}_{3}{ }^{-} \mathrm{CIMS}$ spectra obtained during $\mathrm{O}_{3}+\Delta$-3-carene experiments and $\mathrm{NO}_{3}+\Delta$-3-carene experiments; $\mathrm{NO}_{3}{ }^{-} \mathrm{CIMS}$ high resolution (HR) peak list from $\Delta$-3-carene $+\mathrm{NO}_{3}$ experiment; $\mathrm{NO}_{3}{ }^{-}$Clustering Calculations; Estimated Vapor pressures

\section{AUTHOR INFORMATION}

\section{ORCID:}

James N. Smith: 0000-0003-4677-8224

Kristian H. Møller: 0000-0001-8070-8516

Henrik G. Kjaergaard: 0000-0002-7275-8297

\section{Corresponding Authors}

*Theo Kurtén: theo.kurten@helsinki.fi 
*James N. Smith: jimsmith@uci.edu

\section{Author Contributions}

The manuscript was written through contributions of all authors. All authors have given approval to the final version of the manuscript.

\section{ACKNOWLEDGMENTS}

This research was supported by funding from the Academy of Finland, University of Copenhagen, and the US National Science Foundation (NSF) under grant no. AGS-1762098. DD acknowledges financial support from an NSF Graduate Research Fellowship no. DGE-1321846 and GROW travel grant. N.M. thanks the Jenny and Antti Wihuri foundation for financial support.We thank the CSC-IT Center for Science in Espoo, Finland, for computational resources.

\section{REFERENCES}

(1) Myhre, G., Shindell, D., Bréon, F,-M., Collins, W., Fuglestvedt, J., Huang, J., Koch, D., Lamarque, J.-F., Lee, D., Mendoza, B., Nakajima, T., Robock, A., Stephens, G., Takemura, T., and Zhang, H. Climate Change 2013: The Physical Science Basis: Contribution of Working Group I Contribution to the Fifth Assessment Report of the Intergovernmental Panel on Climate Change; Stocker, T.F., D. Qin, G.-K. Plattner, M. Tignor, S.K. Allen, J. Boschung, A. Nauels, Y. Xia, V. B. and P. M. M. (eds. ., Ed.; Cambridge, United Kingdom Cambridge University Press, 2014. C2013: Cambridge,

United Kingdom and New York, NY, 2014; pp 659-740. https://doi.org/10.1017/ 
CBO9781107415324.018.

(2) Shrivastava, M.; Cappa, C. D.; Fan, J.; Goldstein, A. H.; Guenther, A. B.; Jimenez, J. L.; Kuang, C.; Laskin, A.; Martin, S. T.; Ng, N. L.; et al. Recent Advances in Understanding Secondary Organic Aerosol: Implications for Global Climate Forcing. Rev. Geophys. 2017, 55 (2), 509-559. https://doi.org/10.1002/2016RG000540.

(3) Ng, N. L.; Brown, S. S.; Archibald, A. T.; Atlas, E.; Cohen, R. C.; Crowley, J. N.; Day, D. A.; Donahue, N. M.; Fry, J. L.; Fuchs, H.; et al. Nitrate Radicals and Biogenic Volatile Organic Compounds: Oxidation, Mechanisms, and Organic Aerosol. Atmos. Chem. Phys. 2017, 17 (3), 2103-2162. https://doi.org/10.5194/acp-17-2103-2017.

(4) Pye, H. O. T.; Chan, A. W. H.; Barkley, M. P.; Seinfeld, J. H. Global Modeling of Organic Aerosol: The Importance of Reactive Nitrogen (NOx and NO3). Atmos. Chem. Phys. 2010, 10 (22), 11261-11276. https://doi.org/10.5194/acp-10-11261-2010.

(5) Hoyle, C. R.; Boy, M.; Donahue, N. M.; Fry, J. L.; Glasius, M.; Guenther, A.; Hallar, A. G.; Huff Hartz, K.; Petters, M. D.; Petäjä, T.; et al. A Review of the Anthropogenic Influence on Biogenic Secondary Organic Aerosol. Atmos. Chem. Phys. 2011, 11 (1), 321-343. https://doi.org/10.5194/acp-11-321-2011.

(6) Griffin, R. J.; Cocker, D. R.; Flagan, R. C.; Seinfeld, J. H. Organic Aerosol Formation from the Oxidation of Biogenic Hydrocarbons. J. Geophys. Res. Atmos. 1999, 104 (D3), 3555-3567. https://doi.org/10.1029/1998JD100049.

(7) Fry, J. L.; Draper, D. C.; Barsanti, K. C.; Smith, J. N.; Ortega, J.; Winkler, P. M.; Lawler, M. J.; Brown, S. S.; Edwards, P. M.; Cohen, R. C.; et al. Secondary Organic Aerosol 
Formation and Organic Nitrate Yield from NO 3 Oxidation of Biogenic Hydrocarbons. Environ. Sci. Technol. 2014, 48 (20), 11944-11953. https://doi.org/10.1021/es502204x.

(8) Atkinson, R.; Arey, J. Atmospheric Degradation of Volatile Organic Compounds. Chem. Rev. 2003, 103 (12), 4605-4638. https://doi.org/10.1021/cr0206420.

(9) Orlando, J. J.; Tyndall, G. S. Laboratory Studies of Organic Peroxy Radical Chemistry: An Overview with Emphasis on Recent Issues of Atmospheric Significance. Chem. Soc. Rev. 2012, 41 (19), 6294. https://doi.org/10.1039/c2cs35166h.

(10) Crounse, J. D.; Nielsen, L. B.; Jørgensen, S.; Kjaergaard, H. G.; Wennberg, P. O. Autoxidation of Organic Compounds in the Atmosphere. J. Phys. Chem. Lett. 2013, 4 (20), 3513-3520. https://doi.org/10.1021/jz4019207.

(11) Otkjær, R. V.; Jakobsen, H. H.; Tram, C. M.; Kjaergaard, H. G. Calculated Hydrogen Shift Rate Constants in Substituted Alkyl Peroxy Radicals. J. Phys. Chem. A 2018, 122 (43), 8665-8673. https://doi.org/10.1021/acs.jpca.8b06223.

(12) Møller, K. H.; Bates, K. H.; Kjaergaard, H. G. The Importance of Peroxy Radical Hydrogen-Shift Reactions in Atmospheric Isoprene Oxidation. J. Phys. Chem. A 2019, 123 (4), 920-932. https://doi.org/10.1021/acs.jpca.8b10432.

(13) Bianchi, F.; Kurtén, T.; Riva, M.; Mohr, C.; Rissanen, M. P.; Roldin, P.; Berndt, T.; Crounse, J. D.; Wennberg, P. O.; Mentel, T. F.; et al. Highly Oxygenated Organic Molecules (HOM) from Gas-Phase Autoxidation Involving Peroxy Radicals: A Key Contributor to Atmospheric Aerosol. Chem. Rev. 2019, 119 (6), 3472-3509. https://doi.org/10.1021/acs.chemrev.8b00395. 
(14) Orlando, J. J.; Tyndall, G. S.; Wallington, T. J. The Atmospheric Chemistry of Alkoxy Radicals. Chem. Rev. 2003, 103 (12), 4657-4690. https://doi.org/10.1021/cr020527p.

(15) Kurtén, T.; Møller, K. H.; Nguyen, T. B.; Schwantes, R. H.; Misztal, P. K.; Su, L.; Wennberg, P. O.; Fry, J. L.; Kjaergaard, H. G. Alkoxy Radical Bond Scissions Explain the Anomalously Low Secondary Organic Aerosol and Organonitrate Yields From $\alpha$-Pinene + NO3. J. Phys. Chem. Lett. 2017, $8 \quad$ (13), 2826-2834. https://doi.org/10.1021/acs.jpclett.7b01038.

(16) Vereecken, L.; Peeters, J. Decomposition of Substituted Alkoxy Radicals—Part I: A Generalized Structure-Activity Relationship for Reaction Barrier Heights. Phys. Chem. Chem. Phys. 2009, 11 (40), 9062. https://doi.org/10.1039/b909712k.

(17) Vereecken, L.; Peeters, J. A Structure-Activity Relationship for the Rate Coefficient of HMigration in Substituted Alkoxy Radicals. Phys. Chem. Chem. Phys. 2010, 12 (39), 12608. https://doi.org/10.1039/c0cp00387e.

(18) Brophy, P.; Farmer, D. K. A Switchable Reagent Ion High Resolution Time-of-Flight Chemical Ionization Mass Spectrometer for Real-Time Measurement of Gas Phase Oxidized Species: Characterization from the 2013 Southern Oxidant and Aerosol Study. Atmos. Meas. Tech. 2015, 8 (7), 2945-2959. https://doi.org/10.5194/amt-8-2945-2015.

(19) Kurtén, T.; Tiusanen, K.; Roldin, P.; Rissanen, M.; Luy, J.-N.; Boy, M.; Ehn, M.; Donahue, N. $\alpha$-Pinene Autoxidation Products May Not Have Extremely Low Saturation Vapor Pressures Despite High O:C Ratios. J. Phys. Chem. A 2016, 120 (16), 2569-2582. https://doi.org/10.1021/acs.jpca.6b02196. 
(20) Hyttinen, N.; Rissanen, M. P.; Kurtén, T. Computational Comparison of Acetate and Nitrate Chemical Ionization of Highly Oxidized Cyclohexene Ozonolysis Intermediates and Products. J. Phys. Chem. A 2017, 121 (10), 2172-2179. https://doi.org/10.1021/acs.jpca.6b12654.

(21) Ehn, M.; Thornton, J. A.; Kleist, E.; Sipilä, M.; Junninen, H.; Pullinen, I.; Springer, M.; Rubach, F.; Tillmann, R.; Lee, B.; et al. A Large Source of Low-Volatility Secondary Organic Aerosol. Nature 2014, 506 (7489), 476-479. https://doi.org/10.1038/nature13032.

(22) Møller, K. H.; Otkjaer, R. V; Hyttinen, N.; Kurtén, T.; Kjaergaard, H. G.; Ø, C. CostEffective Implementation of Multi-Conformer Transition State Theory for Peroxy Radical Hydrogen Shift Reactions. J. Phys. Chem. A 2016, 120 (51), 10072-10087. https://doi.org/10.1021/acs.jpca.6b09370.

(23) Lee, C.; Yang, W.; Parr, R. G. Development of the Colle-Salvetti Correlation-Energy Formula into a Functional of the Electron Density. Phys. Rev. B 1988, 37 (2), 785-789. https://doi.org/10.1103/PhysRevB.37.785.

(24) Becke, A. D. Density-functional Thermochemistry. III. The Role of Exact Exchange. $J$. Chem. Phys. 1993, 98 (7), 5648-5652. https://doi.org/10.1063/1.464913.

(25) Frisch, M. J.; Trucks, G. W.; Schlegel, H. B.; Scuseria, G. E.; Robb, M. A.; Cheeseman, J. R.; Scalmani, G.; Barone, V.; Mennucci, B.; Petersson, G. A.; Nakatsuji, H.; Caricato, M.; Li, X.; Hratchian, H. P.; Izmaylov, A. F.; Bloino, J.; Zheng, G.; Sonnenb, D. J. Gaussian 09. Gaussian, Inc.: Wallingford, CT 2009.

(26) Dunning, T. H. Gaussian Basis Sets for Use in Correlated Molecular Calculations. I. The 
Atoms Boron through Neon and Hydrogen. J. Chem. Phys. 1989, 90 (2), 1007-1023. https://doi.org/10.1063/1.456153.

(27) Kendall, R. A.; Dunning, T. H.; Harrison, R. J. Electron Affinities of the First-row Atoms Revisited. Systematic Basis Sets and Wave Functions. J. Chem. Phys. 1992, 96 (9), 67966806. https://doi.org/10.1063/1.462569.

(28) Chai, J.-D.; Head-Gordon, M. Long-Range Corrected Hybrid Density Functionals with Damped Atom-Atom Dispersion Corrections. Phys. Chem. Chem. Phys. 2008, 10 (44), 6615. https://doi.org/10.1039/b810189b.

(29) Myllys, N.; Elm, J.; Kurtén, T. Density Functional Theory Basis Set Convergence of Sulfuric Acid-Containing Molecular Clusters. Comput. Theor. Chem. 2016, 1098, 1-12. https://doi.org/10.1016/j.comptc.2016.10.015.

(30) Neese, F. The ORCA Program System. Wiley Interdiscip. Rev. Comput. Mol. Sci. 2012, 2 (1), 73-78. https://doi.org/10.1002/wcms.81.

(31) Riplinger, C.; Sandhoefer, B.; Hansen, A.; Neese, F. Natural Triple Excitations in Local Coupled Cluster Calculations with Pair Natural Orbitals. J. Chem. Phys. 2013, 139 (13), 134101. https://doi.org/10.1063/1.4821834.

(32) Myllys, N.; Elm, J.; Halonen, R.; Kurtén, T.; Vehkamäki, H. Coupled Cluster Evaluation of the Stability of Atmospheric Acid-Base Clusters with up to 10 Molecules. J. Phys. Chem. A 2016, 120 (4), 621-630. https://doi.org/10.1021/acs.jpca.5b09762.

(33) Riplinger, C.; Neese, F. An Efficient and near Linear Scaling Pair Natural Orbital Based Local Coupled Cluster Method. J. Chem. Phys. 2013, 138 (3), 034106. 
https://doi.org/10.1063/1.4773581.

(34) Eckart, C. The Penetration of a Potential Barrier by Electrons. Phys. Rev. 1930, 35 (11), 1303-1309. https://doi.org/10.1103/PhysRev.35.1303.

(35) De Haan, D. O.; Brauers, T.; Oum, K.; Stutz, J.; Nordmeyer, T.; Finlayson-Pitts, B. J. Heterogeneous Chemistry in the Troposphere: Experimental Approaches and Applications to the Chemistry of Sea Salt Particles. Int. Rev. Phys. Chem. 1999, 18 (3), 343-385. https://doi.org/10.1080/014423599229910.

Draper, D. C.; Farmer, D. K.; Desyaterik, Y.; Fry, J. L. A Qualitative Comparison of Secondary Organic Aerosol Yields and Composition from Ozonolysis of Monoterpenes at Varying Concentrations of NO 2. Atmos. Chem. Phys 2015, 15, 12267-12281. https://doi.org/10.5194/acp-15-12267-2015.

(37) Eisele, F. L.; Tanner, D. J. Measurement of the Gas Phase Concentration of H2SO4 and Methane Sulfonic Acid and Estimates of H2SO4 Production and Loss in the Atmosphere. J. Geophys. Res. 1993, 98 (D5), 9001. https://doi.org/10.1029/93JD00031.

(38) Draper, D. C., Smith, J. N., Fry, J. L., Kurten, T., Kjaergaard, H. G. Supporting Data for Formation of Highly Oxidized Molecules from NO3 Radical Oxidation of $\Delta$-3-Carene: A Computational Mechanism. 2019. https://doi.org/https://doi.org/10.7280/D1VT0B.

(39) Holland, F.; Hofzumahaus, A.; Schäfer, J.; Kraus, A.; Pätz, H. Measurements of OH and $\mathrm{HO}_{2}$ Radical Concentrations and Photolysis Frequencies during BERLIOZ. J. Geophys. Res. 2003, 108 (D4), 8246. https://doi.org/10.1029/2001JD001393.

(40) Richters, S.; Pfeifle, M.; Olzmann, M.; Berndt, T. Endo-Cyclization of Unsaturated RO2 
Radicals from the Gas-Phase Ozonolysis of Cyclohexadienes. Chem. Commun. 2017, 53 (29), 4132-4135. https://doi.org/10.1039/C7CC01350G.

(41) Xu, L.; Møller, K. H.; Crounse, J. D.; Otkjær, R. V.; Kjaergaard, H. G.; Wennberg, P. O. Unimolecular Reactions of Peroxy Radicals Formed in the Oxidation of $\alpha$-Pinene and $\beta$ Pinene by Hydroxyl Radicals. J. Phys. Chem. A 2019, 123 (8), 1661-1674. https://doi.org/10.1021/acs.jpca.8b11726.

(42) Kirkby, J.; Duplissy, J.; Sengupta, K.; Frege, C.; Gordon, H.; Williamson, C.; Heinritzi, M.; Simon, M.; Yan, C.; Almeida, J.; et al. Ion-Induced Nucleation of Pure Biogenic Particles. Nature 2016, 533 (7604), 521-526. https://doi.org/10.1038/nature17953.

(43) Lehtipalo, K.; Yan, C.; Dada, L.; Bianchi, F.; Xiao, M.; Wagner, R.; Stolzenburg, D.; Ahonen, L. R.; Amorim, A.; Baccarini, A.; et al. Multicomponent New Particle Formation from Sulfuric Acid, Ammonia, and Biogenic Vapors. Sci. Adv. 2018, 4 (12), eaau5363. https://doi.org/10.1126/sciadv.aau5363.

(44) Pankow, J. F.; Asher, W. E. SIMPOL.1: A Simple Group Contribution Method for Predicting Vapor Pressures and Enthalpies of Vaporization of Multifunctional Organic Compounds. Atmos. Chem. Phys. 2008, 8 (10), 2773-2796. https://doi.org/10.5194/acp-82773-2008.

(45) Goldstein, A. H.; Galbally, I. E. Known and Unexplored Organic Constituents in the Earth's Atmosphere. Environ. Sci. Technol. 2007, 41 (5), 1514-1521. https://doi.org/10.1021/es072476p.

(46) Donahue, N. M.; Robinson, A. L.; Trump, E. R.; Riipinen, I.; Kroll, J. H. Volatility and 
Aging of Atmospheric Organic Aerosol. In Topics in current chemistry; 2012; Vol. 339, pp 97-143. https://doi.org/10.1007/128_2012_355. 
For Table of Contents Only:

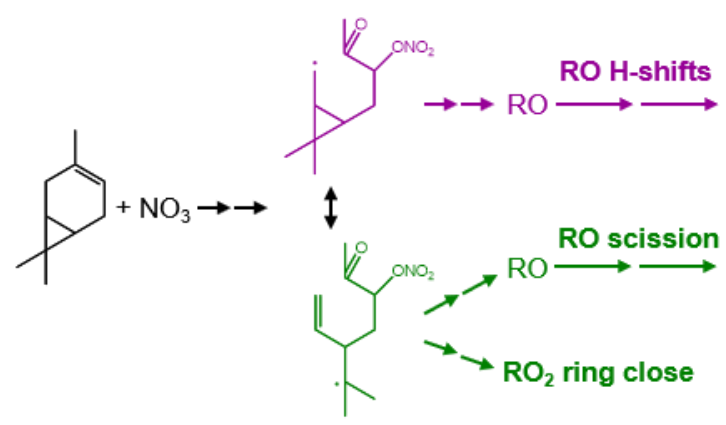

